\title{
Prediction of Post-resection Prognosis Using the ADV Score for Huge Hepatocellular Carcinomas $\geq 13 \mathrm{~cm}$
}

\author{
Shin Hwang, Ki-Hun Kim, Deok-Bog Moon, Chul-Soo Ahn, Tae-Yong Ha, Gi-Won Song, Dong-Hwan Jung, \\ Gil-Chun Park
}

Department of Surgery, Asan Medical Center, University of Ulsan College of Medicine, Seoul, Korea

Received Nov. 19, 2020

Revised Jan. 12, 2021

Accepted Jan. 20, 2021
Background/Aims: Multiplication of a-fetoprotein, des- $\gamma$-carboxy prothrombin, and tumor volume (ADV score) is a surrogate marker for post-resection prognosis of hepatocellular carcinoma (HCC). This study aimed to validate the predictive power of the ADV score-based prognostic prediction model for patients with solitary huge HCC.

Methods: Of 3,018 patients, 100 patients who underwent hepatic resection for solitary HCC $\geq 13 \mathrm{~cm}$ between 2008 and 2012 were selected.

Results: The median tumor diameter and tumor volume were $15.0 \mathrm{~cm}$ and $886 \mathrm{~mL}$, respectively. Tumor recurrence and overall survival (OS) rates were $70.7 \%$ and $66.0 \%$ at one year and $84.9 \%$ and $34.0 \%$ at five years, respectively. Microvascular invasion (MVI) was the only independent risk factor for disease-free survival (DFS) and OS. DFS and OS, stratified by ADV score with 1-log intervals, showed significant prognostic contrasts $(P=0.007$ and $P=0.017$, respectively). DFS and OS, stratified by ADV score with a cut-off of 8-log, showed significant prognostic contrasts ( $P=0.014$ and $P=0.042$, respectively). The combination of MVI and ADV score with a cut-off of 8-log also showed significant prognostic contrasts in DFS $(P<0.001)$ and OS $(P=0.001)$ considering the number of risk factors. Prognostic contrast was enhanced after combining the MVI and ADV score.

Conclusions: The prognostic prediction model with the ADV score could reliably predict the risk of tumor recurrence and long-term patient survival outcomes in patients with solitary huge $\mathrm{HCC} \geq 13 \mathrm{~cm}$. The results of this study suggest that our prognostic prediction models can be used to guide surgical treatment and post-resection follow-up for patients with huge HCCs. (J Liver Cancer 2021;21:45-57)

Keywords: Hepatocellular carcinoma; Resection; Recurrence; Microvascular invasion; Tumor biology

\section{Corresponding author: Shin Hwang}

Department of Surgery, Asan Medical Center, University of Ulsan College of Medicine, 88 Olympic-ro 43-gil, Songpa-gu, Seoul 05505, Korea Tel. +82-2-3010-3930, Fax. +82-2-3010-6701

E-mail; shwang@amc.seoul.kr

https://orcid.org/0000-0002-9045-2531
}

\section{INTRODUCTION}

Hepatocellular carcinoma (HCC), one of the most common malignancies worldwide, is one of the leading causes of cancer-related death. ${ }^{1}$ Huge HCCs with maximal tumor diameter greater than $13 \mathrm{~cm}$ or tumor volume greater than $1,000 \mathrm{~mL}$ are occasionally encountered during the initial di- 
agnosis of a liver mass. Although outcomes of both surgical and non-surgical treatments for huge HCCs are usually unsatisfactory, ${ }^{2}$ a small proportion of patients show acceptably favorable outcomes after hepatic resection (HR). Thus, HR is considered the first-line treatment for huge resectable HCCs in patients with preserved hepatic function. ${ }^{3-6}$ In patients with huge HCCs, post-resection tumor recurrence is very frequent despite complete tumor resection. Thus, overall patient survival is determined by the curability of $\mathrm{HR}$ and subsequent treatment for HCC recurrence, along with the remnant liver functional reserve. ${ }^{3}$

Considering the very high incidence of early post-resection recurrence in patients with huge HCCs, it is beneficial to discern patients with a low risk of tumor recurrence and a high probability of prolonged survival. We have previously demonstrated that multiplication of $\alpha$-fetoprotein (AFP), des-Y-carboxy prothrombin (DCP; proteins induced by vitamin $\mathrm{K}$ antagonist or absence-II), and tumor volume (TV) (AFP-DCP-TV [ADV] score) is an integrated surrogate marker of post-resection and post-transplant prognosis for HCC. ${ }^{7-9}$ The prognostic predictive power of the ADV score is high enough in patients with small- to large-sized HCCs but relatively limited for those with huge HCCs. This study aimed to validate the prognostic impact of the ADV score on patients who underwent resection for solitary huge HCC with a maximal diameter of $\geq 13 \mathrm{~cm}$.

\section{METHODS}

\section{Study design and patient selection}

This was a single-center retrospective study involving a single arm of patients with solitary huge HCC $\geq 13 \mathrm{~cm}$. HR was preferentially performed for patients with huge HCCs who had resectable tumors and preserved liver function. Our institutional liver cancer surgery database was searched extensively to identify patients who underwent HR for solitary HCC $\geq 13 \mathrm{~cm}$ between January 2008 and May 2012. The total number of cases of HR for HCC during the study period was $3,018 .{ }^{10}$ Only patients who underwent HR with curative intent were included in this study. Patients who did not under- go AFP or DCP measurements within 14 days prior to surgery were excluded as their exact ADV score could not be calculated. Patients with DCP measurements showing high cut-off values such as $>2,000,>20,000$, or $>75,000 \mathrm{mAU} / \mathrm{mL}$ were also excluded because of limitations in the quantitative calculation of the ADV score. Of the 3,018 patients, 100 (3.3\%) were included as the final study cohort.

The medical records of the included study patients were retrospectively reviewed. Patients were followed up until October 2020 through review of their medical records and with the assistance of the National Health Insurance Service, resulting in a follow-up period of $\geq 100$ months or until patient death. The study protocol was approved by the Institutional Review Board at the Asan Medical Center (IRB no. 20191347). The requirement for informed consent from patients was waived due to the retrospective nature of this study. This study was performed in accordance with the ethical guidelines of the World Medical Association Declaration of Helsinki 2013.

The primary purpose of this study was to estimate tumor recurrence and patient survival in accordance with the ADV score. The secondary purpose was to determine cut-off values of the ADV score that would be clinically applicable to the resection of huge HCCs.

\section{Preoperative evaluation, surgical procedures, and follow-up}

Preoperative imaging evaluation for HCC included dynamic abdominal and pelvic computed tomography (CT), chest CT, magnetic resonance imaging, and $2{ }^{18} \mathrm{~F}$-fluoro2-deoxy-d-glucose positron emission tomography (FDGPET) scan. Visual comparison of uptake in the HCC region and surrounding non-tumor liver tissues on FDG-PET scan was performed. If the contour of the tumor was definitely identifiable, it was regarded as a hypermetabolic uptake. The hepatic functional reserve was assessed using an indocyanine green retention rate at 15 minutes and evidence of portal hypertension on imaging and endoscopic studies.

The extent of HR was determined based on the proportion of future liver remnant volume after considering tumor-free 
Shin Hwang, et al.

Prognostic prediction with ADV score for $\mathrm{HCC} \geq 13 \mathrm{~cm}$

Table 1. Clinicopathological features of the study patients $(n=100)$

\begin{tabular}{ll}
\hline Characteristic & \multicolumn{1}{c}{ Value } \\
\hline Age (years) & $55.1 \pm 11.9(20-79)$ \\
Sex & \\
Male & $78(78.0)$ \\
Female & $22(22.0)$
\end{tabular}

Background liver disease

Hepatitis B virus infection

$77(77.0)^{*}$

Hepatitis C virus infection

Alcoholic liver disease

$19(19.0)$

Others

$2(2.0)$

Preoperative laboratory profiles

Total bilirubin (mg/dL)

$1.1 \pm 0.5$

Aspartate aminotransferase (IU/L)

$113.1 \pm 110.9$

Alanine aminotransferase (IU/L)

$62.3 \pm 115.5$

Albumin (g/dL)

$3.5 \pm 0.5$

Prothrombin time (INR)

$1.43 \pm 1.21$

Platelet count $(/ \mu \mathrm{L})$ $245.3 \pm 99.1 \times 10^{3}$

Serum AFP

$\begin{array}{lc}<100 \mathrm{ng} / \mathrm{mL} & 33(33.0) \\ \geq 100 \mathrm{ng} / \mathrm{mL} & 67(67.0) \\ \text { Median }(\mathrm{ng} / \mathrm{mL}) & 1,300(1.2-1,420,000) \\ \text { Serum DCP } & \\ <200 \mathrm{mAU} / \mathrm{mL} & 15(15.0) \\ \geq 200 \mathrm{mAU} / \mathrm{mL} & 85(85.0) \\ \text { Median }(\mathrm{mAU} / \mathrm{mL}) & 9,080(16-101,073)\end{array}$

FDG-PET findings $(n=86)$

Isometabolic

$13(15.1)$

Hypermetabolic

$73(84.9)$

ICG-R (\%) $_{15}$

$15.6 \pm 9.6$

History of preoperative HCC treatment

$\begin{array}{ll}\text { No } & 87(87.0) \\ \text { Yes } & 13(13.0)\end{array}$

Preoperative portal vein embolization

No $\quad 97(97.0)$

Yes

$3(3.0)$

Tumor diameter $(\mathrm{cm})$

$16.2 \pm 2.9$

Median (range)

$15.0(13.0-24.5)$

Tumor volume $(\mathrm{mL})$

$1,092.2 \pm 629.2$

Median (range)

$886(452-3,385)$

Microvascular invasion

$\begin{array}{ll}\text { Absent } & 27(27.0) \\ \text { Present } & 73(73.0)\end{array}$

Table 1. Continued

\begin{tabular}{ll}
\hline Characteristic & Value \\
\hline Macrovascular invasion & \\
Absent & $82(82.0)$ \\
Present & $18(18.0)$ \\
Satellite nodules & \\
Absent & $75(75.0)$ \\
Present & $25(25.0)$ \\
Most common Edmondson-Steiner & \\
tumor differentiation (n=523) & \\
I and II & $35(35.0)$ \\
III and IV & $65(65.0)$ \\
Liver cirrhosis & \\
Absent & $72(72.0)$ \\
Present & $28(28.0)$ \\
\hline
\end{tabular}

Values are presented as mean \pm standard deviation (range) or number (\%) unless otherwise indicated.

INR, International Normalized Ratio; AFP, a-fetoprotein; DCP, des$\gamma$-carboxy prothrombin; FDG-PET, $2-{ }^{18}$ F-fluoro-2-deoxy-d-glucose positron emission tomography; ICG- $\mathrm{R}_{15}$, indocyanine green retention test at 15 minutes; HCC, hepatocellular carcinoma.

* Including one case of hepatitis B and C virus co-infection.

Table 2. Extents of hepatic resection

\begin{tabular}{lc}
\hline & Value \\
\hline Extent of hepatectomy & \\
Right trisectionectomy & $4(4.0)$ \\
Right hepatectomy \pm caudate resection & $58(58.0)$ \\
Right anterior sectionectomy & $5(5.0)$ \\
Right posterior sectionectomy & $5(5.0)$ \\
Central bisectionectomy & $5(5.0)$ \\
Left trisectionectomy & $1(1.0)$ \\
Left hepatectomy \pm caudate resection & $15(15.0)$ \\
Left medial sectionectomy & $2(2.0)$ \\
Left lateral sectionectomy & $3(3.0)$ \\
Partial hepatectomy & $2(2.0)$ \\
Concurrent extrahepatic bile duct resection & $3(3.0)$ \\
Curability of hepatic resection & $88(88.0)$ \\
R0 resection & $12(12.0)$ \\
R1 resection &
\end{tabular}


resection margins and hepatic functional reserve. Perioperative evaluation, perioperative follow-up, and treatment for tumor recurrence have been described previously. ${ }^{3,7-9,11-13}$

\section{Calculation of ADV score}

Blood concentrations of AFP and DCP were measured during preoperative assessment. The upper normal ranges of AFP and DCP at our institution were $7.5 \mathrm{ng} / \mathrm{mL}$ and $40 \mathrm{mAU} / \mathrm{mL}$, respectively. As huge HCCs are often not spheroid in shape, the TV was calculated using pathology report data with a formula to measure the volume of an ellipsoid mass as " $(4 / 3) \times \pi \times a \times b \times c$ " (a, b, and $c$ are semi-axes).
Multiplication of AFP $(\mathrm{ng} / \mathrm{mL})$, DCP $(\mathrm{mAU} / \mathrm{mL})$, and TV $(\mathrm{mL})$ indicates the ADV score, which is expressed on a logarithmic scale $(\log 10$ is simply presented as $\log )$.

\section{Statistical analysis}

Continuous variables were analyzed using the Student's $t$ test or Mann-Whitney $U$ test. Incidence variables were compared using the chi-square test or Fisher's exact test. Survival curves were estimated using the Kaplan-Meier method and compared using the log-rank test. Cox proportional hazard regression analysis was used to obtain the hazard ratio and 95\% confidence interval. Harrell's concordance index (c-in-
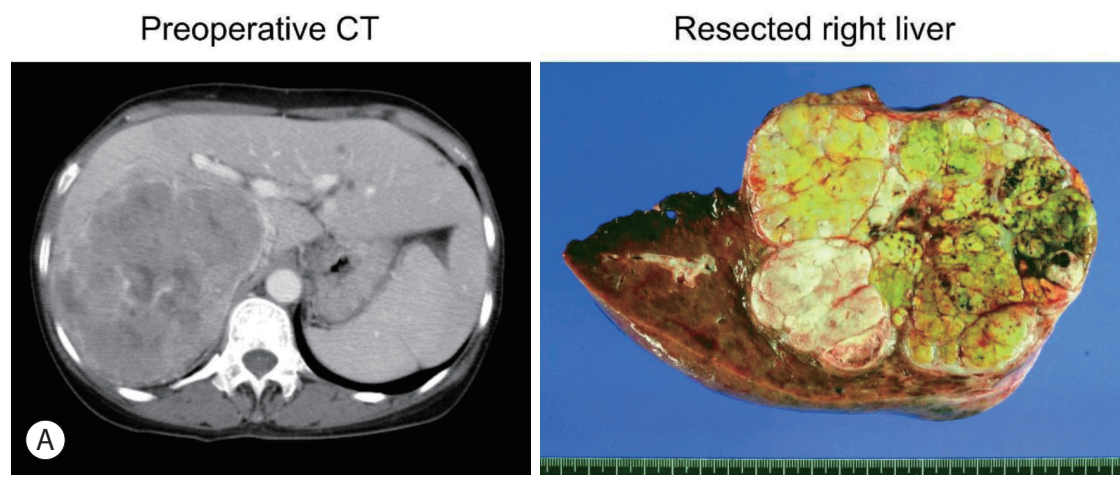

\section{Postoperative CT at 3 months}
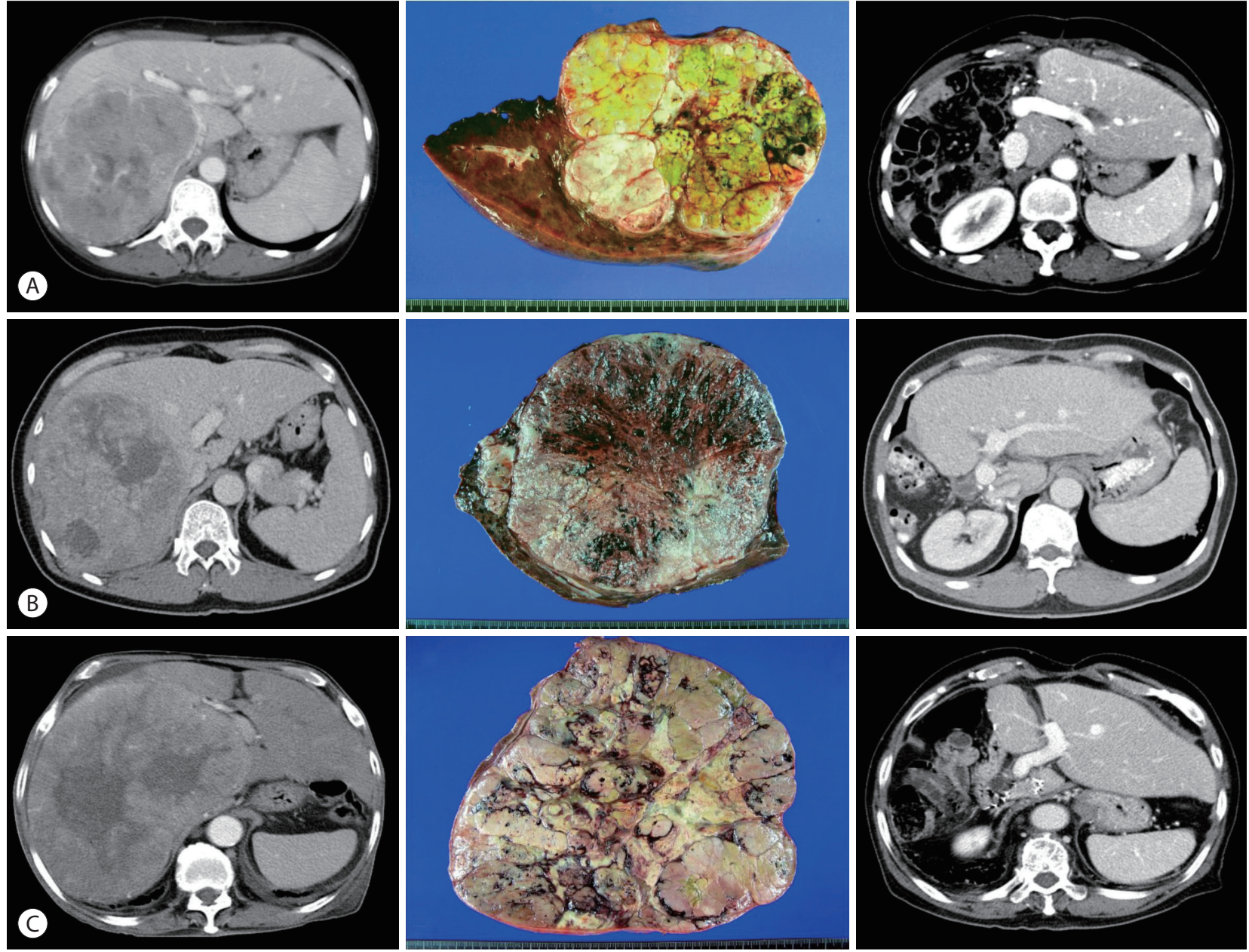

Figure 1. Comparison of preoperative computed tomography (CT) scan, resected right liver specimen, and CT scan taken 3 months after hepatic resection in patients who underwent right hepatectomy. The maximal tumor diameters were $13 \mathrm{~cm}(\mathrm{~A}), 17 \mathrm{~cm}(\mathrm{~B})$, and $20 \mathrm{~cm}(\mathrm{C})$. 
dex) was used for the quantitative assessment of prediction accuracy. A $P$-value $<0.05$ was considered to indicate a statistically significant difference. Statistical analyses were performed using SPSS version 22 (IBM Corp., New York, NY, USA) and Stata version 15 (Stata Corp., College Station, TX, USA).

\section{RESULTS}

\section{Clinical features of patients}

The clinical and pathological features of all 100 study patients are summarized in Table 1. Hepatitis B virus (HBV) infection was present in $77(77.0 \%)$ patients. Thirteen $(13.0 \%)$ patients had a history of treatment for HCC before $\mathrm{HR}$, including transarterial chemoembolization (TACE)/radioembolization with or without other treatment modalities in 10 patients and systemic chemotherapy in three patients. Preoperative right portal vein embolization for right hepatectomy was performed in three $(3.0 \%)$ patients. Preoperative laboratory examinations showed median values of $1,300 \mathrm{ng} / \mathrm{mL}$ (range, 1.2-1,420,000) for AFP and 9,080 mAU/mL (range, 16-101,073) for DCP. The FDG-PET study showed hypermetabolic uptake in 73 (84.9\%) of 86 patients.

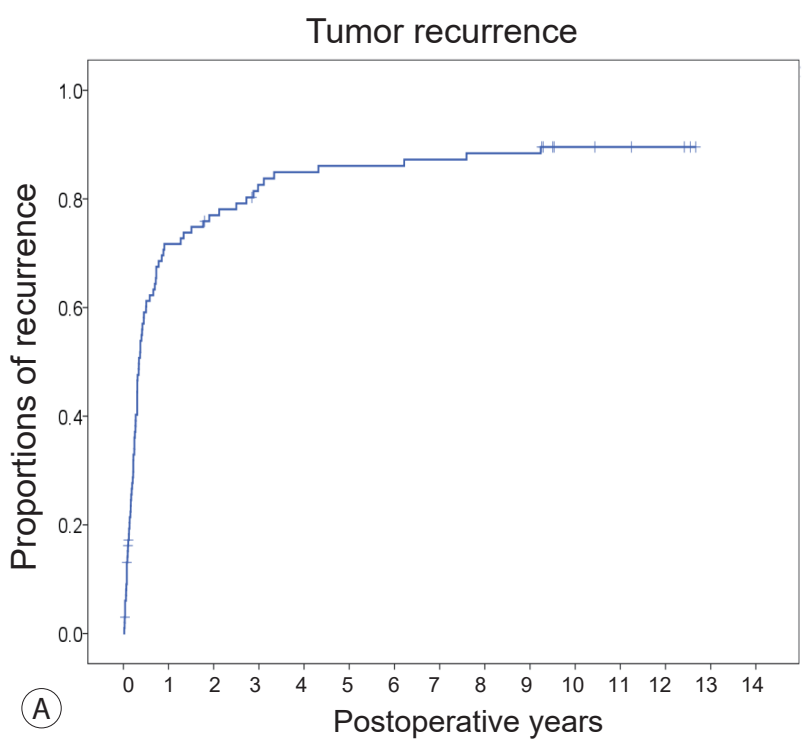

\section{Operative and pathological findings}

Extents of HR are summarized in Table 2. R0 and R1 resections were performed in $88(88.0 \%)$ and $12(12.0 \%)$ patients, respectively. The median tumor diameter was $15.0 \mathrm{~cm}$ (range, 13.0-24.5 cm) and median TV was $886 \mathrm{~mL}$ (range, 452-3,385 mL) (Fig. 1). Pathological studies revealed microvascular invasion (MVI) in $73(73.0 \%)$ patients, macrovascular invasion in $18(18.0 \%)$ patients, satellite nodules in 25 (25.0\%) patients, and liver cirrhosis in 28 (28.0\%) patients (Table 1). In the 10 patients who underwent TACE preoperatively, none showed tumor necrosis of more than $50 \%$.

\section{Tumor recurrence and patient survival}

One patient died during the first month after HR due to sepsis. Thus, the 1-month perioperative mortality rate was $1.0 \%$. Seven patients died during the first 3 months, with an overall 3-month mortality rate of 7.0\%. During the followup period of more than 100 months, tumor recurrence was identified in 84 patients. Prognostic analysis indicated that the cumulative 6-month, 1-year, 3-year, and 5-year tumor recurrence rates were $59.1 \%, 70.7 \%, 82.6 \%$, and $84.9 \%$, respectively (Fig. 2A). All-cause death was observed in 78 patients. The 6-month, 1-year, 3-year, and 5-year overall sur-

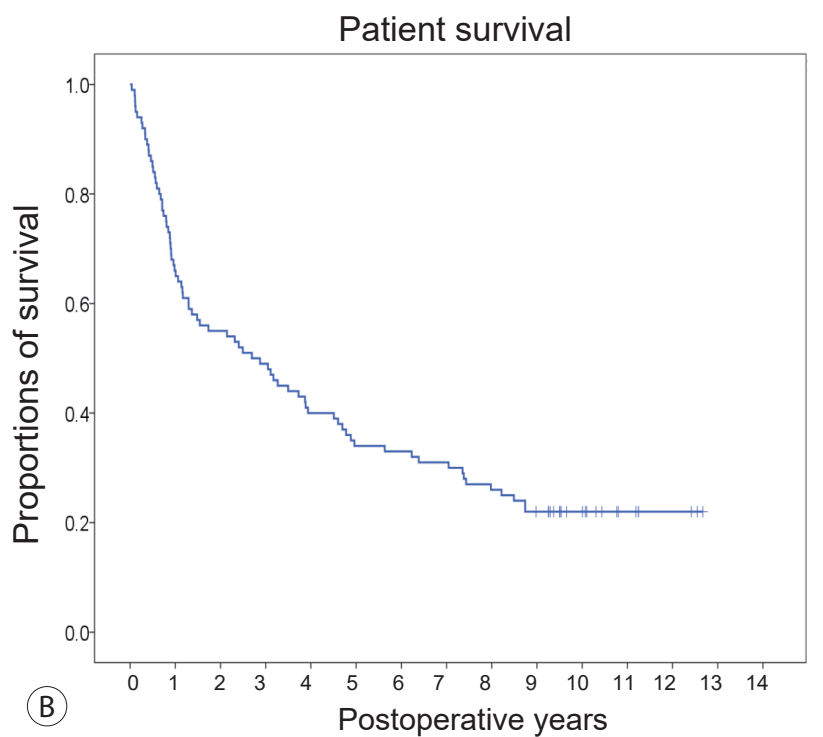

Figure 2. Kaplan-Meier estimation of post-resection tumor recurrence (A) and overall patient survival (B). 
Table 3. Univariate and multivariate analyses of the risk factors associated with tumor recurrence and patient survival

\begin{tabular}{|c|c|c|c|c|c|c|c|c|c|c|c|}
\hline \multirow[b]{3}{*}{ Parameter } & \multirow{3}{*}{$\begin{array}{l}\text { Case } \\
\text { No. }\end{array}$} & \multicolumn{5}{|c|}{ Tumor recurrence } & \multicolumn{5}{|c|}{ Patient survival } \\
\hline & & \multicolumn{2}{|c|}{ Univariate analysis } & \multicolumn{3}{|c|}{ Multivariate analysis } & \multicolumn{2}{|c|}{ Univariate analysis } & \multicolumn{3}{|c|}{ Multivariate analysis } \\
\hline & & $\begin{array}{l}\text { Median } \\
\text { DFS period } \\
\text { (months) }\end{array}$ & $\begin{array}{c}P \text { - } \\
\text { value }\end{array}$ & $\begin{array}{c}\text { Hazard } \\
\text { ratio }\end{array}$ & $95 \% \mathrm{Cl}$ & $\begin{array}{c}P \text { - } \\
\text { value }\end{array}$ & $\begin{array}{l}\text { Median } \\
\text { OS period } \\
\text { (months) }\end{array}$ & $\begin{array}{c}P \text { - } \\
\text { value }\end{array}$ & $\begin{array}{c}\text { Hazard } \\
\text { ratio }\end{array}$ & $95 \% \mathrm{Cl}$ & $\begin{array}{c}P \text { - } \\
\text { value }\end{array}$ \\
\hline Background liver disease & & & 0.031 & & & 0.24 & & 0.31 & & & ND \\
\hline Non-HBV & 23 & 9.4 & & 1 & & & 25.7 & & & & \\
\hline HBV & 77 & 3.7 & & 1.40 & $0.79-2.56$ & & 38.0 & & & & \\
\hline Preoperative AFP & & & 0.40 & & & ND & & 0.048 & & & 0.18 \\
\hline$<100 \mathrm{ng} / \mathrm{mL}$ & 33 & 3.7 & & & & & 56.3 & & 1 & & \\
\hline$\geq 100 \mathrm{ng} / \mathrm{mL}$ & 67 & 4.2 & & & & & 17.7 & & 1.40 & $0.85-2.30$ & \\
\hline Serum DCP & & & 0.64 & & & ND & & 0.21 & & & ND \\
\hline$<200 \mathrm{mAU} / \mathrm{mL}$ & 15 & 5.5 & & & & & 47.2 & & & & \\
\hline$\geq 200 \mathrm{mAU} / \mathrm{mL}$ & 85 & 3.8 & & & & & 28.8 & & & & \\
\hline FDG-PET findings & & & 0.004 & & & 0.19 & & 0.024 & & & 0.21 \\
\hline Isometabolic & 13 & 3.7 & & 1 & & & 95.7 & & 1 & & \\
\hline Hypermetabolic & 73 & 8 & & 1.87 & $0.74-4.74$ & & 18.5 & & 1.87 & $0.71-4.91$ & \\
\hline Microvascular invasion & & & $<0.001$ & & & 0.007 & & $<0.001$ & & & 0.020 \\
\hline Absent & 27 & 34.6 & & 1 & & & 88.6 & & 1 & & \\
\hline Present & 73 & 3.1 & & 2.42 & $1.27-4.61$ & & 7.1 & & 2.10 & $1.12-3.91$ & \\
\hline Macrovascular invasion & & & 0.031 & & & 0.46 & & 0.53 & & & ND \\
\hline Absent & 82 & 4.5 & & 1 & & & 34.5 & & & & \\
\hline Present & 18 & 2.7 & & 1.24 & $0.71-2.18$ & & 15.5 & & & & \\
\hline Satellite nodule & & & 0.001 & & & 0.071 & & 0.011 & & & 0.99 \\
\hline Absent & 75 & 5.5 & & 1 & & & 38.1 & & 1 & & \\
\hline Present & 25 & 2.9 & & 1.63 & $0.96-2.77$ & & 9.6 & & 1.54 & $0.92-2.59$ & \\
\hline Tumor diameter & & & 0.68 & & & ND & & 0.66 & & & ND \\
\hline$<15 \mathrm{~cm}$ & 44 & 3.7 & & & & & 39.2 & & & & \\
\hline$\geq 15 \mathrm{~cm}$ & 56 & 4.1 & & & & & 18.5 & & & & \\
\hline Tumor volume & & & 0.52 & & & ND & & 0.73 & & & ND \\
\hline$<886 \mathrm{~mL}$ & 49 & 3.7 & & & & & 37.3 & & & & \\
\hline$\geq 886 \mathrm{~mL}$ & 51 & 4.4 & & & & & 27.7 & & & & \\
\hline Liver cirrhosis & & & 0.85 & & & ND & & 0.49 & & & ND \\
\hline Absent & 72 & 4.5 & & & & & 32.3 & & & & \\
\hline Present & 28 & 3.0 & & & & & 25.7 & & & & \\
\hline Type of curability & & & 0.091 & & & 0.61 & & 0.036 & & & 0.13 \\
\hline R0 resection & 88 & 4.5 & & 1 & & & 37.3 & & 1 & & \\
\hline $\mathrm{R} 1$ resection & 12 & 2.1 & & 1.20 & $0.61-2.38$ & & 10.6 & & 1.68 & $0.87-3.26$ & \\
\hline
\end{tabular}

DFS, disease-free survival; 95\% Cl, 95\% confidence interval; OS, overall survival; ND, not done; HBV, hepatitis B virus; AFP, a-fetoprotein; DCP, desY-carboxy prothrombin; FDG-PET, $2{ }^{-18}$ F-fluoro-2-deoxy-d-glucose positron emission tomography. 
vival (OS) rates were $85.0 \%, 66.0 \%, 49.0 \%$, and $34.0 \%$, respectively (Fig. 2B).

The sites of the first tumor recurrence were intrahepatic in $61(72.6 \%)$ patients, extrahepatic in $19(22.6 \%)$ patients (lung in 13 , bone in 3 , adrenal gland in 2 , peritoneum in 1), and multiple intrahepatic and extrahepatic in four (4.8\%) patients. The lung was the most frequent initial extrahepatic metastatic site $(n=13)$. Every available locoregional treatment was performed according to the sites and patterns of tumor recurrence. However, seven patients received only the best supportive care due to worsened general conditions and/or rapid tumor progression. Due to suboptimal responses of locoregional treatments for tumor recurrence, 35 (41.7\%) patients finally underwent systemic chemotherapy, including sorafenib and other chemotherapeutic agents.

\section{Risk factor analysis for tumor recurrence and patient survival}

Results of univariate and multivariate analyses for tumor recurrence and patient survival are summarized in Table 3. In the univariate analyses, significant risk factors for diseasefree survival (DFS) were HBV infection, hypermetabolic FDG-PET findings, MVI (Fig. 3), macrovascular invasion, satellite nodules, and $\mathrm{R} 1$ resection, whereas significant risk factors for OS were AFP $\geq 100 \mathrm{ng} / \mathrm{mL}$, hypermetabolic FDGPET findings, MVI, satellite nodules, and R1 resection. The multivariate analyses demonstrated that MVI was the only
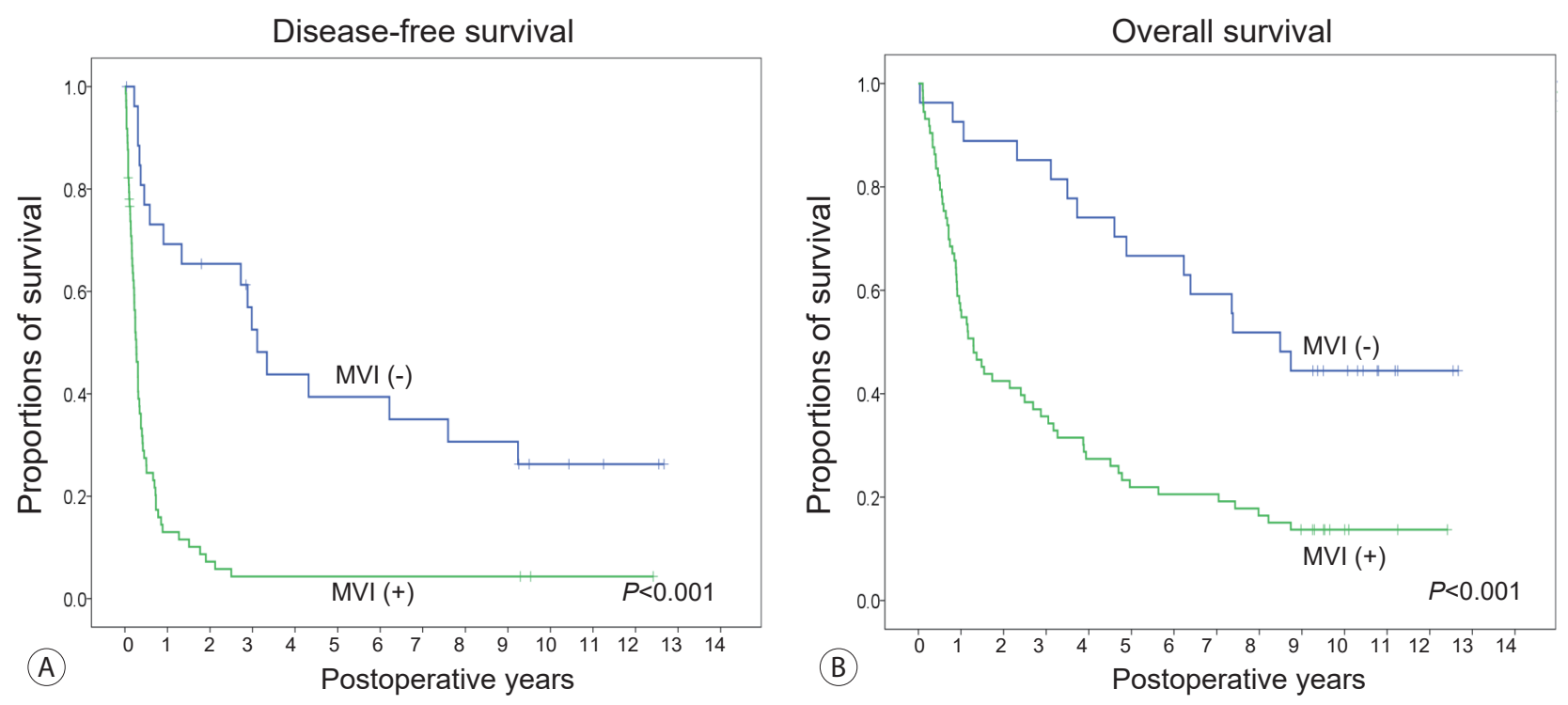

Figure 3. Comparison of the disease-free survival (A) and overall survival (B) curves according to the status of microvascular invasion (MVI).

Table 4. Multivariate analyses with microvascular invasion and ADV score with a cut-off of 8 log

\begin{tabular}{|c|c|c|c|c|c|c|}
\hline & \multicolumn{3}{|c|}{ Disease-free survival } & \multicolumn{3}{|c|}{ Overall survival } \\
\hline & Hazard ratio & $P$-value & $95 \% \mathrm{Cl}$ & Hazard ratio & $P$-value & $95 \% \mathrm{Cl}$ \\
\hline Microvascular invasion & & 0.001 & & & 0.001 & \\
\hline Absent & 1 & & & & & \\
\hline Present & 3.67 & & $2.09-6.45$ & 2.72 & & $1.51-4.93$ \\
\hline ADV score & & 0.098 & & & 0.12 & \\
\hline$\leq 7.9 \log$ & 1 & & & 1 & & \\
\hline$\geq 8.0 \log$ & 1.4 & & $0.91-2.29$ & 1.45 & & $0.96-2.33$ \\
\hline
\end{tabular}

ADV score, a-fetoprotein, des- $\gamma$-carboxy prothrombin, and tumor volume score; 95\% Cl, 95\% confidence interval. 
independent risk factor for both DFS and OS (Table 4).

\section{Prognostic analysis using the ADV score for DFS and OS}

Patients were stratified according to their ADV scores using $1 \log (10$-fold) intervals as follows: eight $(8.0 \%)$ patients with ADV scores of $\leq 5.9 \log$; seven $(7.0 \%)$ with ADV scores of 6.0-6.9log; seven (7.0\%) with ADV scores of 7.0-7.9log; 16 (16.0\%) with ADV scores of 8.0-8.9log; 15 (15.0\%) with ADV scores of 9.0-9.9log; 18 (18.0\%) with ADV scores of 10.0-10.9log; nine (9.0\%) with ADV scores of 11.0-11.9log; 14 (14.0\%) with ADV scores of 12.0-12.9log; and six (6.0\%) with ADV scores of $\geq 13$.0log. DFS stratified according to the
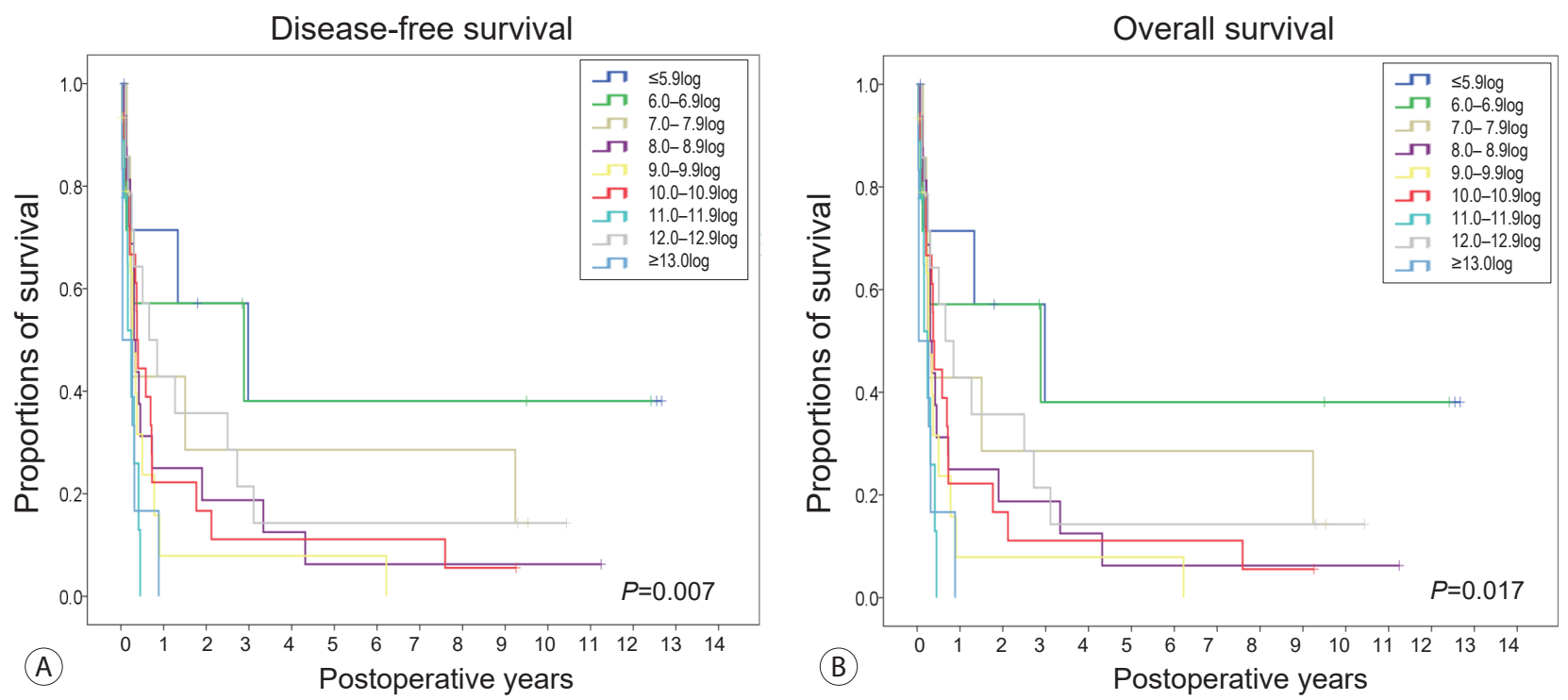

Figure 4. Comparison of the disease-free survival (A) and overall survival (B) curves according to the $\alpha$-fetoprotein, des- $\gamma$-carboxy prothrombin, and tumor volume (ADV) score of 1 log intervals.
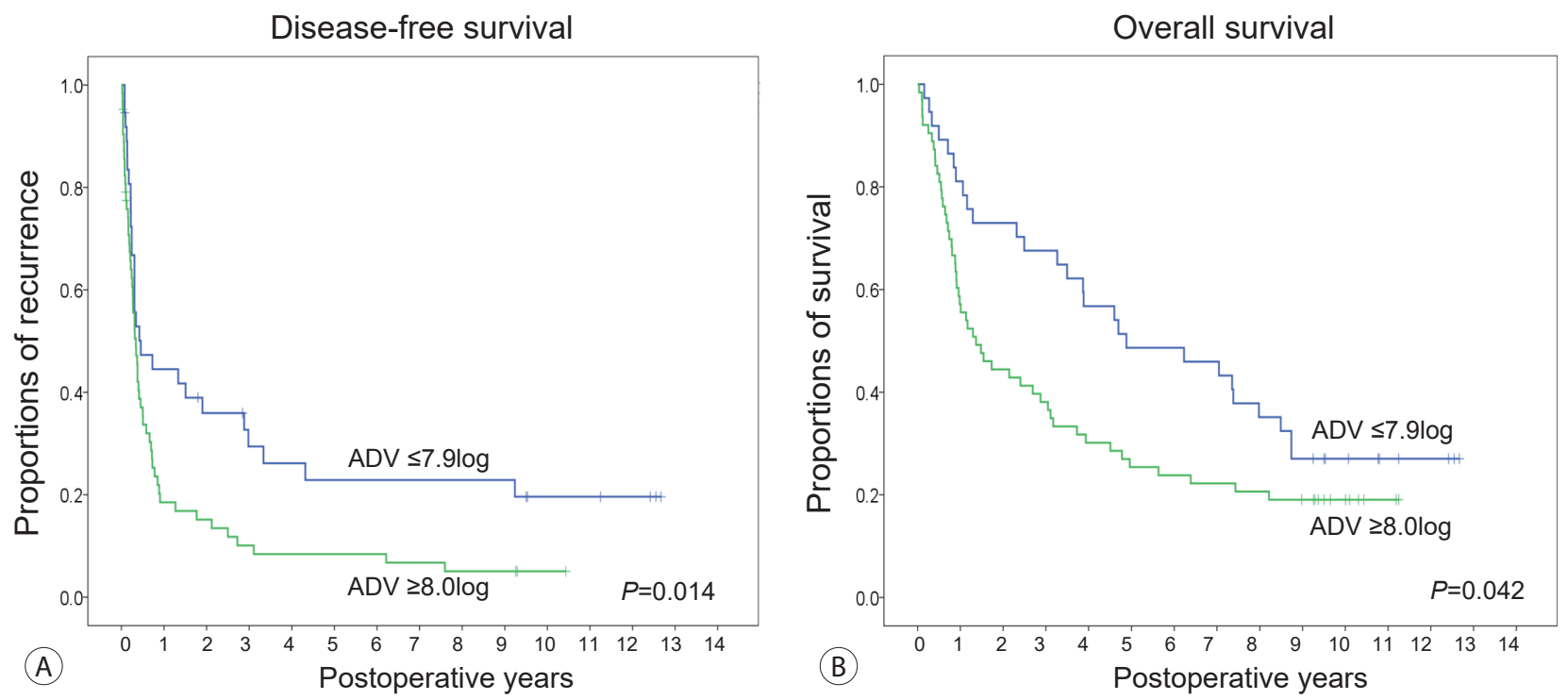

Figure 5. Comparison of the disease-free survival (A) and overall survival (B) curves according to the $\alpha$-fetoprotein, des- $\gamma$-carboxy prothrombin, and tumor volume (ADV) score with a cut-off of 8.0log. 
ADV score at $1 \log$ intervals showed significant prognostic contrasts ( $P=0.007$; Fig. $4 \mathrm{~A}$ ). OS stratified according to the ADV score at $1 \log$ intervals also showed significant prognostic contrasts $(P=0.017$; Fig. 4B).

To enhance the prognostic contrast and to select patients with truly poor prognosis, patients were reclassified into two subgroups with ADV score ranges of $\leq 7.9 \log$ and $\geq 8 \log$ after cluster analysis. Survival analysis according to these two cutoff values showed significant prognostic contrasts in DFS $(P=0.014$; Fig. $5 \mathrm{~A})$ and $\mathrm{OS}(P=0.042$; Fig. $5 \mathrm{~B})$.

\section{Prognostic analysis using a combination of $\mathrm{MVI}$ and the ADV score}

Risk factor analysis showed that MVI was the only independent risk factor for DFS and OS. Harrell's c-index, according to MVI, was 0.63 and 0.62 for DFS and OS, respectively. An ADV score with a cut-off of $8 \log$ was also a significant prognostic factor. Harrell's c-index, according to the ADV score with a cut-off of $8 \log$, was 0.57 and 0.56 for DFS and OS, respectively.

Additional multivariate analyses with these two factors showed that MVI was an independent risk factor for DFS $(P=0.001)$ and OS $(P=0.001)$. ADV score with a cut-off of 8log showed a marginal significance for DFS $(P=0.098)$ and OS $(P=0.12)$. Although the prognostic impact of these two parameters was not equally strong, we considered them as two independent risk factors; the combination of MVI and the ADV score with a cut-off of 8log (MVI-ADV score) resulted in three subgroups with 0,1 , and 2 risk factors. This prognostic prediction model using the MVI-ADV score showed significant prognostic contrasts in DFS $(P<0.001$; Fig. $6 \mathrm{~A})$ and $\mathrm{OS}(P=0.001$; Fig. $6 \mathrm{~B})$. Harrell's c-index, according to the MVI-ADV score, was 0.68 and 0.67 for DFS and OS, respectively.

\section{DISCUSSION}

Tumor size is traditionally considered one of the most important prognostic factors for the post-resection prognosis of HCC. We have previously demonstrated that post-resection prognosis gradually worsens with increasing tumor size from $1 \mathrm{~cm}$ to $10 \mathrm{~cm}$ regardless of the MVI status. ${ }^{11}$ In addition, the incidence of MVI reportedly increases with HCC size. ${ }^{14}$ We found that the incidence of MVI showed a progressive increase from $4.1 \%$ for HCCs $<2 \mathrm{~cm}$ to $30.7 \%$ for HCCs of 8.1-9.9 cm. ${ }^{11}$ In the present study, huge HCCs $\geq 13 \mathrm{~cm}$ presented with MVI in $73 \%$ of cases. It is frequently observed
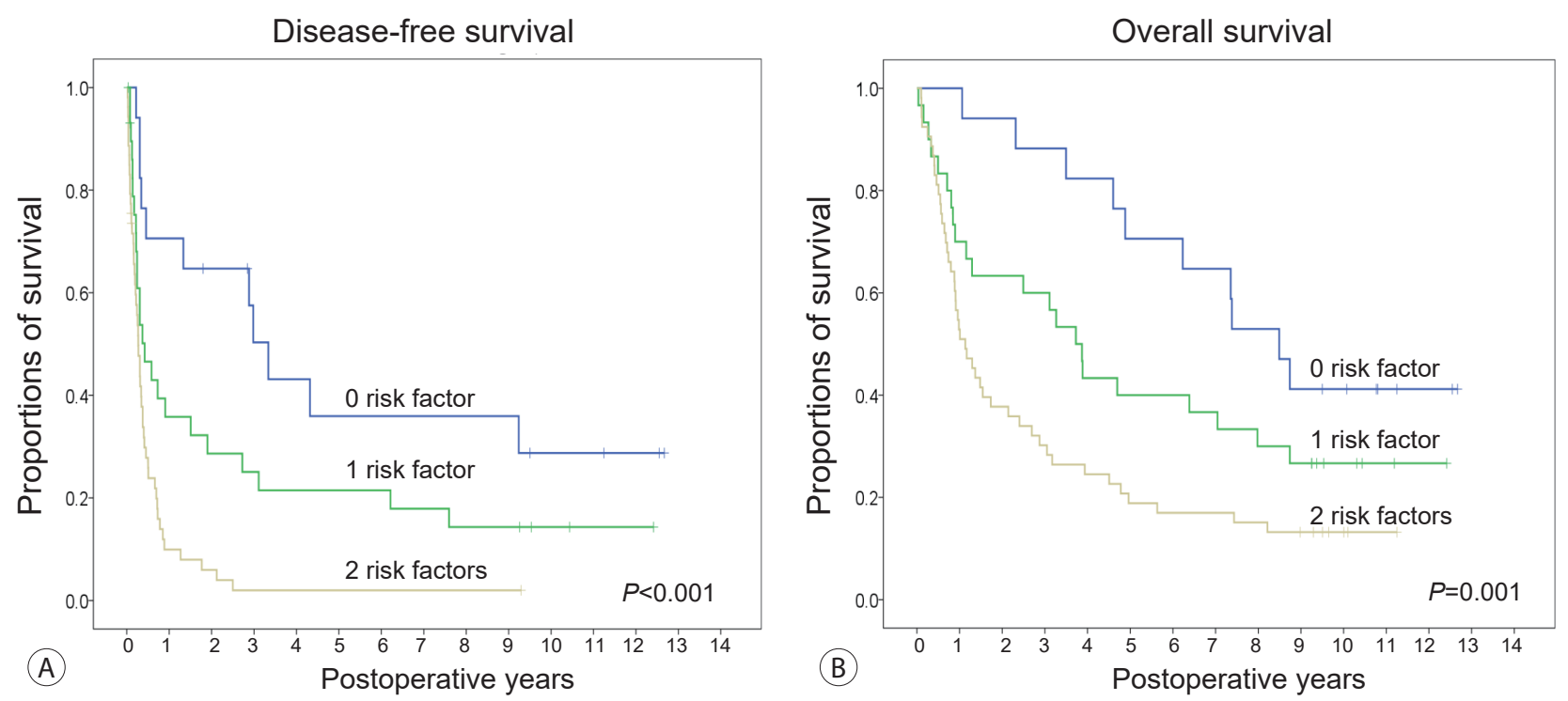

Figure 6. Comparison of the disease-free survival (A) and overall survival (B) curves according to the number of risk factors (presence of microvascular invasion and $a$-fetoprotein, des- - -carboxy prothrombin, and tumor volume [ADV] score $\geq 8.0 \mathrm{log}$ ). 
that HCC becomes biologically more aggressive with progressive growth of the tumor, showing a higher incidence of MVI and higher expression of AFP and DCP. Consequently, the prognosis of patients with large HCCs worsens with tumor growth. Contrarily, a small proportion of patients with huge HCCs have shown unexpectedly favorable long-term survival after HR. ${ }^{15}$ These patients may benefit from HR. Thus, accurate prediction of post-resection prognosis is essential for deciding the treatment plan for patients with huge HCCs.

Before predicting post-resection prognosis, the feasibility of HR should be considered. It is generally accepted that there is no limit to the tumor size that precludes HR, particularly for solitary large HCC, if a patient's hepatic functional reserve permits the corresponding extent of HR. There are two important aspects regarding the operability of huge HCCs: operative safety and surgical curability. HR of huge HCCs usually requires demanding surgical procedures known to increase the risk of massive bleeding. It is important to perform step-by-step approaches, such as initial feeding artery ligation and anterior approach for hepatic parenchymal transection, to minimize intraoperative bleeding. ${ }^{16-18}$ A large abdominal incision with or without extension to the chest wall helps provide a wide operative field, which facilitates mobilization of the huge tumor-bearing right liver. As a huge tumor occupies a certain portion of the liver, the feasible extents of HR are often comparable to those of partial hepatectomy. It is reasonable to design the extent of HR after considering patient safety first. Thus, there is no reason to stick to systematic resection. ${ }^{3,7-11,19-22}$ In fact, nearly all HRs for huge HCCs are not considered as systematic resections because of the high incidence of intrahepatic metastases in the future remnant liver. ${ }^{23,24}$

We have previously developed a prognostic prediction model for HR of large HCCs $\geq 10 \mathrm{~cm}$ using four independent parameters: AFP $\geq 100 \mathrm{ng} / \mathrm{mL}$, hypermetabolic FDG-PET findings, MVI, and satellite nodules. ${ }^{3}$ This prognostic prediction model has been validated through a multicenter study, ${ }^{25}$ in which its predictive power has been demonstrated to be reliably high. Cluster analysis has enabled us to successfully stratify patients into three subgroups with $0-1,2$, and 3-4 risk factors. However, this prediction model includes two pathological parameters that are unavailable during preoperative assessment. We developed a prognostic prediction model with the ADV score to eliminate this limitation. The ADV score is an integrated surrogate marker of post-resection prognosis for HCC as well as a quantifiable parameter reflecting the oncological aggressiveness of HCC. The clinical usability of the ADV score has been well demonstrated in an increasing number of studies regarding HR and liver transplantation. $^{7-9,25}$

Reliable calculation of the ADV score before surgery is a matter of concern for the preoperative prediction of patients with HCC. We used CT volumetry to measure individual TVs. The definition provided in the Modified Response Evaluation Criteria in Solid Tumors (mRECIST) ${ }^{26}$ was applied to measure viable TV in patients who underwent prior HCC treatment. In patients who have undergone TACE before HR, TV can be estimated through volumetric measurement of the contrast-enhancing portions of tumors, and lipiodolized zones were considered as non-enhancing lesions as adopted in the mRECIST criteria. This can offset the different therapeutic effects of preceding HCC treatments. It has been reported that the results of pretransplant imaging have reliable correlations with explant/resection pathology regarding the size of viable tumors. ${ }^{27-29}$ Although we did not measure TV before HR in the present study, we believe that there exists a close correlation between the pathology report-based TV and CT volumetry-based TV using the mRECIST criteria. In our recent study on living donor liver transplantation for HCC, the correlation analyses between the pretransplant and pathological findings in 843 patients showed high correlations between viable tumor number (Spearman's correlation coefficient rho $[\rho]=0.845, P<0.001)$, maximal tumor size $(\rho=0.688, P<0.001)$, total TV $(\rho=0.736, P<0.001)$, and $\operatorname{ADV}$ score $(\rho=0.895, P<0.001) .^{30}$

In our previous study with 526 cases of $\mathrm{HCC} \geq 8 \mathrm{~cm},{ }^{25}$ the cut-off of the ADV score was set at 7log after cluster analysis. Patient grouping according to a combination of ADV at $7 \mathrm{log}$ and FDG-PET findings exhibited significant differences in DFS and OS, which were comparable to those of the abovementioned prognostic prediction model with four risk fac- 
tors. However, the prognostic model combining the ADV score at $7 \log$ and FDG-PET findings was not sufficiently reliable for patients with huge HCCs because the ADV score cut-off of $7 \log$ was too low to stratify the patients with huge HCCs. Thus, in the present study, we raised the cut-off ADV score to $8 \log$, which resulted in clear prognostic contrast in DFS and OS. In practice, the reliable cut-off value of the ADV score varies depending on the characteristics of the study group. The cut-off ADV score was lowered to 4log for patients with solitary HCC $\leq 5 \mathrm{~cm}$, whereas it was raised to $7 \log$ for those with HCC $\geq 8 \mathrm{~cm}$ and to $9 \log$ for those with HCC combined with portal vein tumor thrombus. ${ }^{7-9,25}$

Prognostic prediction with only the ADV score is available before HR; thus, it can be used for treatment planning. After HR, additional information on MVI is available; thus, a combination of the ADV score and MVI can enhance the power of prognostic prediction. In the present study, a combination of MVI and the ADV score cut-off at 8log enabled us to stratify the patients into three subgroups with 0,1 , and 2 risk factors, and DFS and OS were inversely correlated with the number of risk factors. Our prognostic models with only the ADV score and MVI-ADV score combination can be separately applied to clinical practice before and after HR. We have applied them to determine the intervals of followup imaging studies, particularly during the first year. We also used the preoperative ADV score using CT volumetry to design the tailored extent of HR.

We have previously reported that de novo or residual intrahepatic metastasis was detected in $41.9 \%$ of patients who have undergone HR for large HCCs $\geq 10 \mathrm{~cm}$ and preemptive transarterial chemoinfusion (TACI)/TACE at postoperative 1 month. ${ }^{3,19,31}$ A combination of surgery with curative intent for huge HCCs and subsequent postoperative 1-month TACI/TACE appears to be a reasonable therapeutic option in the current setting in Korea. We have previously demonstrated that satellite nodules were an independent risk factor for intrahepatic metastasis at postoperative 1 month. Thus, performing preemptive 1-month TACI/TACE for HCC with satellite nodules has been strongly suggested. ${ }^{3,19}$ Although the prognosis of patients with intrahepatic metastasis at 1 month was still inferior to that of patients without early intrahepatic metastasis, we presume that timely or early detection and treatment of small metastatic HCC lesions would benefit these patients, without causing any harm. ${ }^{32}$

The present study has some limitations. This was a singlecenter retrospective study in an HBV-endemic area. Hence, it will be necessary to validate our results in other regions to extend our results to patients with HCC of various etiologies. Another limitation was that we selected only patients with solitary HCC to avoid bias from inevitable confounding variables.

In conclusion, the prognostic prediction model using the ADV score could reliably predict the risk of tumor recurrence and long-term patient survival outcomes in patients with solitary huge HCC $\geq 13 \mathrm{~cm}$. The results of this study suggest that our prognostic prediction model can be used to guide surgical treatment and post-resection follow-up in patients with huge HCCs.

\section{FUNDING}

This study was supported by a Research Fund from the Korean Liver Cancer Association (Grant No. 2019 to Shin Hwang).

\section{AUTHOR CONTRIBUTIONS}

Conceptualization: Hwang S. Data curation: Kim KH, Moon DB, Ahn CS and Park GC. Formal analysis: Hwang S. Funding acquisition: Hwang S. Methodology: Ha TY, Song GW and Jung DH. Project administration: Hwang S. Visualization: Hwang S. Writing -original draft: Hwang S. Writing - review \& editing: Hwang $S$.

\section{Conflicts of Interest}

The authors have no conflicts to disclose.

\section{REFERENCES}

1. Forner A, Llovet JM, Bruix J. Hepatocellular carcinoma. Lancet 2012;379:1245-1255.

2. Huang YH, Wu JC, Chen SC, Chen $\mathrm{CH}$, Chiang JH, Huo TI, et al. 
Survival benefit of transcatheter arterial chemoembolization in patients with hepatocellular carcinoma larger than $10 \mathrm{~cm}$ in diameter. Aliment Pharmacol Ther 2006;23:129-135.

3. Hwang S, Lee YJ, Kim KH, Ahn CS, Moon DB, Ha TY, et al. Longterm outcome after resection of huge hepatocellular carcinoma $\geq 10 \mathrm{~cm}$ : single-institution experience with 471 patients. World J Surg 2015;39:2519-2528.

4. Yamashita Y, Taketomi A, Shirabe K, Aishima S, Tsuijita E, Morita $K$, et al. Outcomes of hepatic resection for huge hepatocellular carcinoma ( $\geq 10 \mathrm{~cm}$ in diameter). J Surg Oncol 2011;104:292-298.

5. Zhou YM, Li B, Xu DH, Yang JM. Safety and efficacy of partial hepatectomy for huge $(\geq 10 \mathrm{~cm})$ hepatocellular carcinoma: a systematic review. Med Sci Monit 2011;17:RA76-RA83.

6. Tsoulfas G, Mekras A, Agorastou P, Kiskinis D. Surgical treatment for large hepatocellular carcinoma: does size matter? ANZ J Surg 2012;82:510-517.

7. Hwang S, Song GW, Lee YJ, Kim KH, Ahn CS, Moon DB, et al. Multiplication of tumor volume by two tumor markers is a post-resection prognostic predictor for solitary hepatocellular carcinoma. J Gastrointest Surg 2016;20:1807-1820.

8. Jung DH, Hwang S, Lee YJ, Kim KH, Song GW, Ahn CS, et al. Small hepatocellular carcinoma with low tumor marker expression benefits more from anatomical resection than tumors with aggressive biology. Ann Surg 2019;269:511-519.

9. Hwang S, Moon DB, Kim KH, Ahn CS, Song GW, Jung DH, et al. Prognostic accuracy of the ADV score following resection of hepatocellular carcinoma with portal vein tumor thrombosis. J Gastrointest Surg 2020 Sep 19. doi: 10.1007/s11605-020-04800-6. [Epub ahead of print].

10. Cho HD, Hwang S, Lee YJ, Park KM, Kim KH, Kim JC, et al. Changes in the types of liver diseases requiring hepatic resection: a single-institution experience of 9016 cases over a 10-year period. Korean J Hepatobiliary Pancreat Surg 2016;20:49-52.

11. Hwang S, Lee YJ, Kim KH, Ahn CS, Moon DB, Ha TY, et al. The impact of tumor size on long-term survival outcomes after resection of solitary hepatocellular carcinoma: single-institution experience with 2558 patients. J Gastrointest Surg 2015;19:1281-1290.

12. Hwang S, Ha TY, Song GW, Jung DH, Ahn CS, Moon DB, et al. Quantified risk assessment for major hepatectomy via the indocyanine green clearance rate and liver volumetry combined with standard liver volume. J Gastrointest Surg 2015;19:1305-1314.

13. The Korean Association for the Study of the Liver. KASL clinical practice guidelines: management of chronic hepatitis B. Clin Mol Hepatol 2016;22:18-75.

14. Pawlik TM, Delman KA, Vauthey JN, Nagorney DM, Ng IO, Ikai I, et al. Tumor size predicts vascular invasion and histologic grade: Implications for selection of surgical treatment for hepatocellular carcinoma. Liver Transpl 2005;11:1086-1092.
15. Yang LY, Fang F, Ou DP, Wu W, Zeng ZJ, Wu F. Solitary large hepatocellular carcinoma: a specific subtype of hepatocellular carcinoma with good outcome after hepatic resection. Ann Surg 2009;249:118-123.

16. Zhou YM, Sui CJ, Zhang XF, Li B, Yang JM. Anterior approach combined with infrahepatic inferior vena cava clamping right hepatic resection for large hepatocellular carcinoma: a prospective randomized controlled trial. Medicine (Baltimore) 2016;95:e4159.

17. Wang XB, Yu QM, Yu PF, Zhang YL, Yang LT, Zhang ZW, et al. Surgical treatment of huge hepatocarcinoma with invasion or severe adhesion of diaphragm using the technique of orthotopic liver resection. Hepatogastroenterology 2015;62:153-156.

18. Huang JS, Dai WD, Miao XY, Zhong DW, Xiong SZ, Hu JX. Nullmargin bisegmentectomy VII-VIII for hepatocellular carcinoma in cirrhotic patients. Hepatogastroenterology 2012;59:1706-1709.

19. Shin HN, Hwang S, Kim KH, Ahn CS, Moon DB, Ha TY, et al. Role of the 1-month protocol transarterial chemoinfusion in detecting intrahepatic metastasis after resection of large hepatocellular carcinoma greater than $10 \mathrm{~cm}$. Korean J Hepatobiliary Pancreat Surg 2013:17:157-161.

20. Eguchi S, Kanematsu T, Arii S, Okazaki M, Okita K, Omata M, et al. Comparison of the outcomes between an anatomical subsegmentectomy and a non-anatomical minor hepatectomy for single hepatocellular carcinomas based on a Japanese nationwide survey. Surgery 2008;143:469-475.

21. Kitamura K, Hatano E, Higashi T, Seo S, Nakamoto Y, Yamanaka K, et al. Preoperative FDG-PET predicts recurrence patterns in hepatocellular carcinoma. Ann Surg Oncol 2012;19:156-162.

22. Ishii T, Hatano E, Yasuchika K, Taura K, Seo S, Uemoto S. High risk of lung metastasis after resection of hepatocellular carcinoma more than $7 \mathrm{~cm}$ in diameter. Surg Today 2014;44:1900-1905.

23. Park MJ, Kim YK, Lee MW, Lee WJ, Kim YS, Kim SH, et al. Small hepatocellular carcinomas: improved sensitivity by combining gadoxetic acid-enhanced and diffusion-weighted MR imaging patterns. Radiology 2012;264:761-770.

24. Sano K, Ichikawa T, Motosugi U, Sou H, Muhi AM, Matsuda M, et al. Imaging study of early hepatocellular carcinoma: usefulness of gadoxetic acid-enhanced MR imaging. Radiology 2011;261:834844.

25. Hwang S, Joh JW, Wang HJ, Kim DG, Kim KS, Suh KS, et al. Prognostic prediction models for resection of large hepatocellular carcinoma: a Korean multicenter study. World J Surg 2018;42:25792591.

26. Lencioni R, Llovet JM. Modified RECIST (mRECIST) assessment for hepatocellular carcinoma. Semin Liver Dis 2010;30:52-60.

27. Botea F, Marconi M, Lutman F, Balzarini L, Roncalli M, Montorsi M, et al. Radiological estimation of size in colorectal liver metastases: is it reliable? Comparison with post-resectional measurements. 
Updates Surg 2010;62:21-26.

28. Galizia MS, Töre HG, Chalian H, Yaghmai V. Evaluation of hepatocellular carcinoma size using two-dimensional and volumetric analysis: effect on liver transplantation eligibility. Acad Radiol 2011;18:1555-1560.

29. Kim HD, Shim JH, Kim GA, Shin YM, Yu E, Lee SG, et al. Optimal methods for measuring eligibility for liver transplant in hepatocellular carcinoma patients undergoing transarterial chemoembolization. J Hepatol 2015;62:1076-1784.

30. Hwang S, Song GW, Ahn CS, Kim KH, Moon DB, Ha TY, et al. Quantitative prognostic prediction using ADV score for hepato- cellular carcinoma following living donor liver transplantation. J Gastrointest Surg 2021 Feb 2. doi: 10.1007/s11605-021-04939-w. [Epub ahead of print].

31. Lau WY, Lai EC, Lau SH. The current role of neoadjuvant/adjuvant/ chemoprevention therapy in partial hepatectomy for hepatocellular carcinoma: a systematic review. Hepatobiliary Pancreat Dis Int 2009;8:124-133.

32. Li KW, Li X, Wen TF, Lu WS. The effect of postoperative TACE on prognosis of HCC: an update. Hepatogastroenterology 2013:60:248-251. 